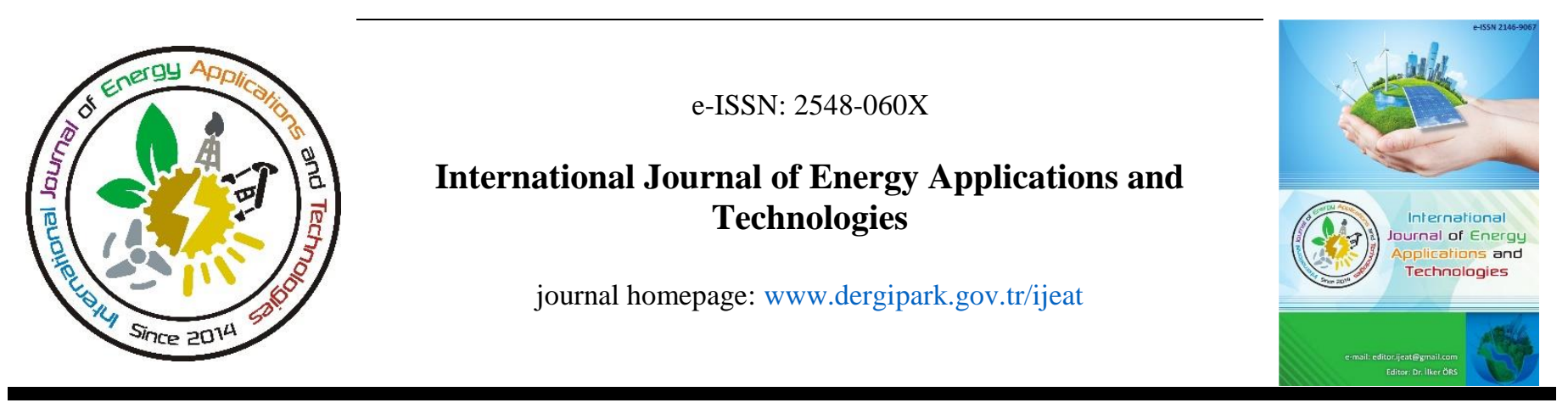

Original Research Article

\title{
A comparative analysis of four-pole brushless DC motors with different slot and winding arrangement based on THD values
}

hosted by JourkinalPark

\author{
Cemil Ocak ${ }^{1, *}$, Adem Dalcalı ${ }^{2}$ \\ ${ }^{1}$ Vocational College of Technical Sciences, Gazi University, Ankara, Turkey \\ ${ }^{2}$ Electrical and Electronics Engineering, Bandırma Onyedi Eylül University Bandırma, Balıkesir, Turkey
}

\author{
ARTICLE INFO \\ * Corresponding author \\ cemilocak@gazi.edu.tr \\ Received January 8, 2020 \\ Accepted April 7, 2020 \\ Published by Editorial Board \\ Members of IJEAT \\ (C) This article is distributed by \\ Turk Journal Park System under \\ the CC 4.0 terms and conditions. \\ doi: 10.31593/ijeat.669064
}

\begin{abstract}
Brushless DC motors (BLDC) are widely used in variable speed drive applications. Nowadays the relationship between the number of poles, slots and winding arrangements in BLDC motors continues to be a very challenging topic. The main objective of this work was to develop and compare four-pole BLDC motors with different slot numbers $(6,12$ and 15) and winding arrangements. Three-dimensional finite element analysis (FEA) was conducted to characterize the proposed designs. The Total Harmonic Distortion (THDv) which tells the amount of harmonics present in the voltage have been obtained and compared based on the different slot numbers and winding arrangement. In the study, an extensive investigation of the THDv values in four-pole BLDC motors having different slot and winding configurations has been carried out. From the simulated results it is evident that the lowest THDv and corresponding sinusoidal back emf can be obtained by implementing 15 slots within four-pole designs. The performance values have been examined comparatively by analysing the motors at the rated condition.
\end{abstract}

\section{Introduction}

The torque speed characteristics of conventional DC motors are linear. However, excitation is done mechanically with brush and collector assembly. This causes frequent motor failure. BLDC motors have been developed to overcome this negative situation and to provide the torque speed characteristic of DC motors. BLDC motors are electronically commutated motors [1]. BLDCs are a class of synchronous motors and consist of silicon sheets whose armature is placed one after the other, armature windings and rotor with permanent magnets. The back electromotive force (emf) formed in BLDCs is trapezoidal. Thus, this back electromotive force provides an increase in the power-toweight ratio [1,2].

There are two main factors that allow the development of BLDCs. The first of these is the production of high energy density magnets with the development of material technology. Another is the decrease in the cost of power electronic elements due to developments in semiconductor technology. The use of magnets with high energy density has resulted in significant reductions in costs by producing more compact machines $[3,4]$. Improvements in power electronics have also made it possible to design a drive circuit that increases reliability and simplicity.

BLDC motors have high efficiency, low inertia, long life, low noise, low manufacturing cost, easy speed control, and a wide torque-speed curve. Because of these properties, BLDC motors have a wide range of applications in the automotive, aerospace, ventilation systems, healthcare and home appliances sectors [5-10].

Studies on BLDC's generally focus on magnet geometries and motor control $[11,12]$. Recent studies on the interaction 
between the number of poles and the number of slots in electrical machines have also been conducted [13-15].

Studies on optimization of total harmonic distortion can be classified into two groups. The first one is to use control methods, and the second one is to make geometric changes in the design of the machine. In [16] high frequency harmonic components of the BLDC motors are optimized by using an $\mathrm{RC}$ filter which is connected to the input. With the designed filter, the THD value of the phase voltage has been reduced from $62 \%$ to $31 \%$ and the THD value of the line current has been reduced from $47 \%$ to $14.7 \%$. In [17] the cascaded $\mathrm{H}$ bridge multilevel inverter with current control reduces the effects of harmonic components in the switching frequency and its multiples. In permanent magnet machines the position, the structure and the magnetization direction of the magnet affect the performance of the machine. In an internal magnet BLDC motor, four different magnet positions and the effect of magnetization direction of these magnets have been examined and $64 \%$ improvement has been realized according to the first design [18]. Similarly, THD performances have been investigated in a BLDC motor whose direction of magnetization has specified as parallel, radial and concentration. The highest harmonic distortion has been observed in radial directional motor with high number of slots [19]. The structure of the magnets can be changed by adjusting the offset value. Thus, the efficiency, the cogging torque, and the THD values can be optimized. In [20] FEA has been performed by changing offset value of BLDC motor between $5-30 \mathrm{~mm}$. The THD value has been reduced $15.8 \%$ to $2.11 \%$ by using $30 \mathrm{~mm}$ offset value.

This study obtained the $\mathrm{THD}_{\mathrm{V}}$ of the BLDC motors, which are rated at $100 \mathrm{~W}, 3000 \mathrm{rpm} \mathrm{4/6,} \mathrm{4/12} \mathrm{and} \mathrm{4/15} \mathrm{pole/slot}$ numbers, for comparative analysis. The design details of each motor were given in previous studies [21].

\section{Motor Designs with Different Combinations}

Table I presents the characteristics of 4-pole motors with 3 different pole/slot combinations in consequence of analytical and optimization studies.

Table 1. Motor parameters

\begin{tabular}{|c|c|c|c|}
\hline Parameter & $\begin{array}{c}\text { 4 pole / } \\
\text { 6 slot }\end{array}$ & $\begin{array}{c}\text { 4 pole / } \\
\text { 12 slot }\end{array}$ & $\begin{array}{c}\text { 4 pole / } \\
\text { 15 slot }\end{array}$ \\
\hline Stator Outer Diameter $(\mathrm{mm})$ & \multicolumn{3}{|c|}{90} \\
\hline Length (mm) & \multicolumn{3}{|c|}{ M270-35A } \\
\hline Stator Core Material & \multicolumn{3}{|c|}{54.2} \\
\hline Rotor Outer Diameter (mm) & \multicolumn{3}{|c|}{ N40UH } \\
\hline Magnet Type & \multicolumn{3}{|c|}{2} \\
\hline Slot Clearance (mm) & 5 & 2 & 9 \\
\hline Slot Width (mm) & 28 & 13 & 72.53 \\
\hline Net Slot Area (mm $\left.{ }^{2}\right)$ & 233.03 & 106.53 & \\
\hline
\end{tabular}

All the physical and material properties except the slot geometries have been determined to be the same in order to fairly compare the examined motors. The slot geometries have been determined by analytical and finite element analyses to obtain optimal values according to the varying number of slots. Figure 1 provides the cross-sectional views of the BLDC motors subject to the study.

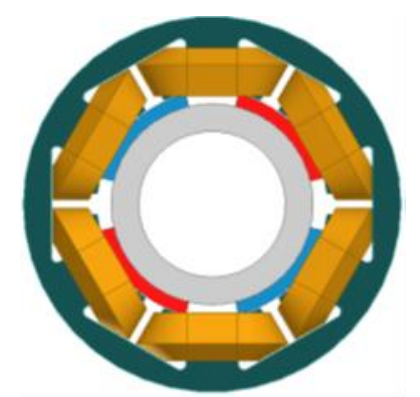

(a)

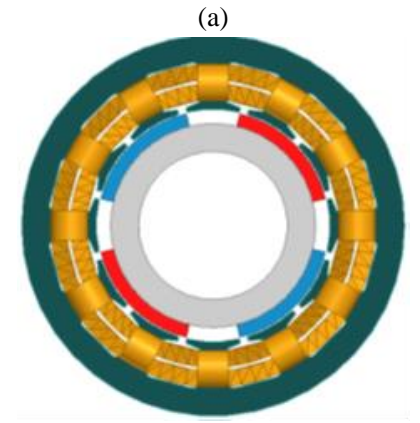

(b)

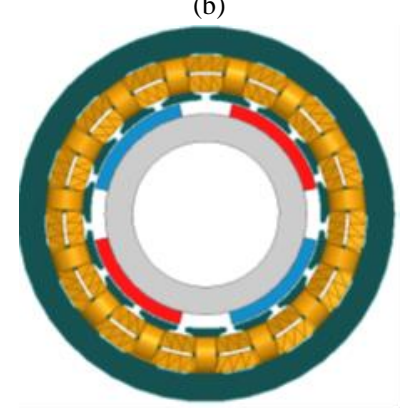

(c)

Fig. 1. A cross-sectional view of the motors a) 4 pole/6 slot, b) 4 pole/12 slot and c) 4 pole/15 slot

Table 2 shows the performance values obtained in the analyses of the designed motors under full load and no load.

Table 2. Motor performance

\begin{tabular}{|c|c|c|c|}
\hline Parameters & $4 / 6$ & $4 / 12$ & $4 / 15$ \\
\hline Efficiency (\%) & 85.32 & 85.16 & 85.29 \\
\hline Output Power (W) & 100 & 100 & 100 \\
\hline Cogging Torque (Nm) & 0.107 & 0.204 & 0.05 \\
\hline Rotor Yoke Flux Density (T) & 1.65 & 1.71 & 1.74 \\
\hline Stator Slot Fill Factor (\%) & 51.0 & 51.3 & 51.6 \\
\hline
\end{tabular}

Table 2 demonstrates the motor performance values. The efficiency values of the motors are about at the same level. This is due to the improvement of each different design in itself. The slot fill factor, which is an important physical limit of the motor design, is determined to be the maximum and the same for all motors.

FEA has been applied to the designs in order to examine the magnetic flux distributions of the motors. The magnetic flux distributions of designed 3D models are given in Figure 2. 


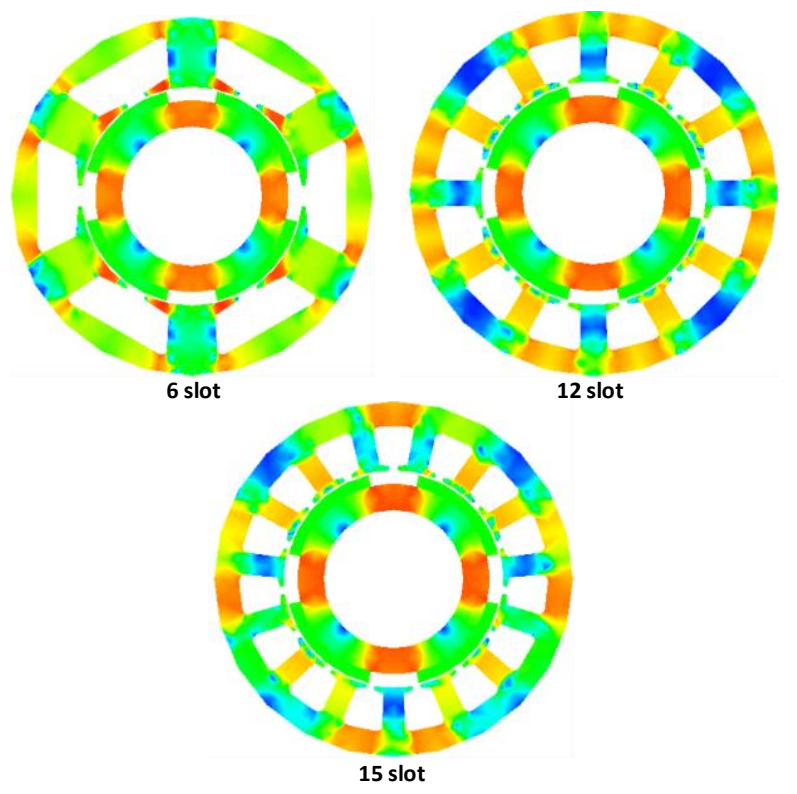

0.00

Mag B (T)

Fig. 2. 3D magnetic flux density distribution of motors

The winding characteristics vary for designs realized in different pole/slot combinations. The optimal winding properties for each pole/slot combination have been tried to be determined. As a result, obtained phase voltage variations of 4 pole/ 6 slot, 4 pole/12 slots and 4 pole/15slot designs are given in Figure 3.

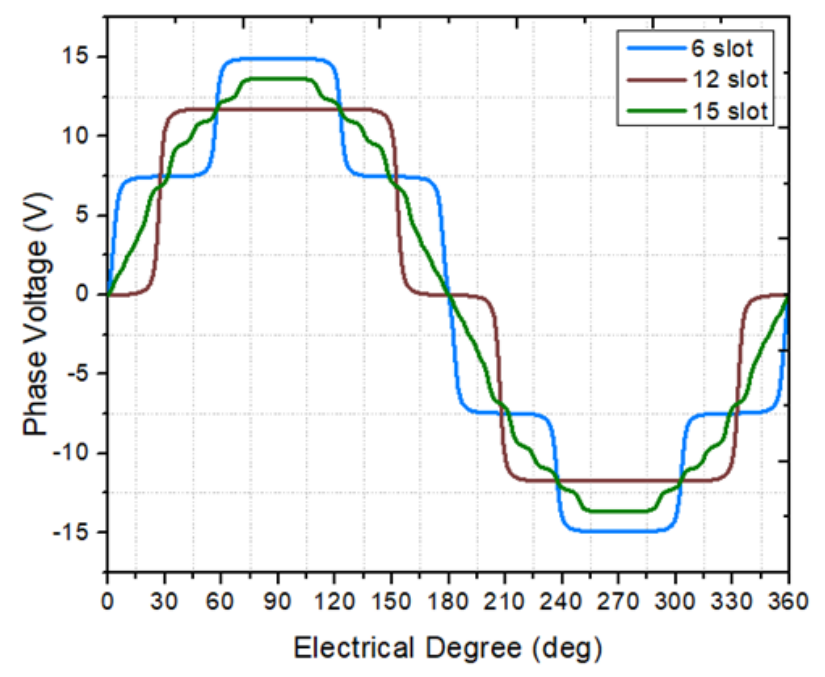

Fig. 3. Phase voltages according to pole/slot combinations

\section{Calculation of Total Harmonics Distortion}

Harmonics are multiples of the fundamental frequency and cause distortions in the voltage and load current. The presence of harmonic components causes distortion of the fundamental wave. In this case, when the electrical machines are examined, the harmonics cause the distortion in the generator voltage [22], overheating of electromechanical equipment [23] and the operation of the motors at noisy and increased $\Delta_{t}$ temperatures [24]. Harmonics cause additional core loss in machines, resulting in excessive heating of the motor core. It is possible to discuss two types of harmonic concepts for electric machine. The first one is the time harmonic due to the source being far from the sinusoidal form, and the other is the space harmonic due to the geometry of the machine.

In BLDC machine, space harmonics depend on the air gap flux waveform. Even though the voltage wave applied to the motor is pure sine, harmonic components can be present in the magnetomotive force due to the slot structure of the motor and the distribution of the winding. Space harmonics can cause acoustic noise, vibration and core saturation. Space harmonics can be optimized by changing the winding configuration or the geometric structure of the machine [2527].

Periodic signals can be expressed as the sum of the sine components at different frequencies. Each of these sine expressions is called Fourier components. This series is known as the Fourier series. The coefficients of the Fourier series can be found through measuring, graphical, and analytical methods [28]. In this study, analyses have been performed by using graphical method. In this method, the average value of each waveform is calculated by dividing the waveform into equally spaced vertical parts. The waveforms to be obtained in the air gap can be expressed mathematically by Fourier series as in Equation 1:

$V(\theta)=A_{0}+\sum_{n=1}^{\infty}\left(A_{n} \times \cos n \theta+B_{n} \sin n \theta\right)$

In the equation, $V$ is the voltage value, $\theta$ is the space angle expressed in electrical degrees, $n$ is the harmonic number and $A_{n}$ and $B_{n}$ are the Fourier coefficients. Fourier coefficients can be expressed in Equation 2 and Equation 3:

$A_{n}=\frac{2}{m} \sum_{k=1}^{m}\left(y_{k} \times \cos \left(n \times \theta_{k}\right)\right)$

and

$B_{n}=\frac{2}{m} \sum_{k=1}^{m}\left(y_{k} \times \sin \left(n \times \theta_{k}\right)\right)$

In the equation, $m$ represents the number of vertical divisions, $n$ the degree of harmonic, and $y_{k}$ is the flux value corresponding to each $\theta_{k}$.

In the Fourier analysis, the number of vertical divisions increases the accuracy of the coefficients. However, the number of excess vertical divisions increases the number of transactions. The voltage waveform can be expressed as the sum of the fundamental and harmonic components as in Equation 4 [29]:

$V_{s}(t)=V_{s 1}(t)+\sum_{h=1} V_{s h}(t)$

Equation 4 represents the line voltage, the fundamental component and the value of the voltage at the harmonic 
frequency. Distortions that occur in the form of voltage or current waves can be expressed in percent of THD. The distortion component of the Equation 4 is obtained by Equation 5 [22]:

$$
V_{d i s}(t)=V_{s}(t)-V_{s 1}(t) \sum_{h=1} V_{s h}(t)
$$

THD in voltage,

$$
T H D \%=100 \times \frac{V_{\text {dis }}}{V_{s 1}}
$$

\section{Simulation Results}

As mentioned in the previous section, in BLDCs, space harmonics depend on the physical structure of the motor. Space harmonics are caused by the slot structure and the nonsinusoidal distribution of the phase windings [30]. In this study, THD values of the machines with different pole/slot numbers are analysed and given in Table 3 .

Table 3. THD values of motors

\begin{tabular}{c|c}
\hline Pole / Slot Combinations & THD (\%) \\
\hline 4 pole/6 slot & 22.30 \\
\hline 4 pole/12 slot & 18.04 \\
\hline 4 pole/15 slot & 3.05 \\
\hline
\end{tabular}

Harmonic spectrums have been obtained by performing a Fourier analysis for the motors with different slot numbers with the help of MATLAB (License number: 40692431) software. Figure 4 presents the graphs of the analyses.

\section{Conclusions}

This paper has given a brief summary of THDv values of four-pole BLDC motors with different winding patterns and slot numbers to contribute to a reduction in the THDv values of BLDC motors. Performance outputs have been obtained for each pole/slot combination that is optimized to offer maximum efficiency and to be compared with a fair criterion. Simulation and comparison results between 6,12 and 15 slot designs demonstrate that lowest THD and corresponding sinusoidal back emf can be obtained by applying 15 slots within four-pole designs in the study, as shown in Table 3. Although they are arranged to offer approximately the same efficiency values in the study, designs with high THD values can present significant problems such as acoustic noise, vibration, saturation risk of core and increased winding $\Delta \mathrm{t}$ temperatures. Therefore, although the nameplates of these motors with different combinations are similar in terms of efficiency, THD values have a significant impact on the motor's operating performance and should be reduced as much as possible in design stage. Authors aim to examine the $\Delta t$ temperatures of each design for future research.

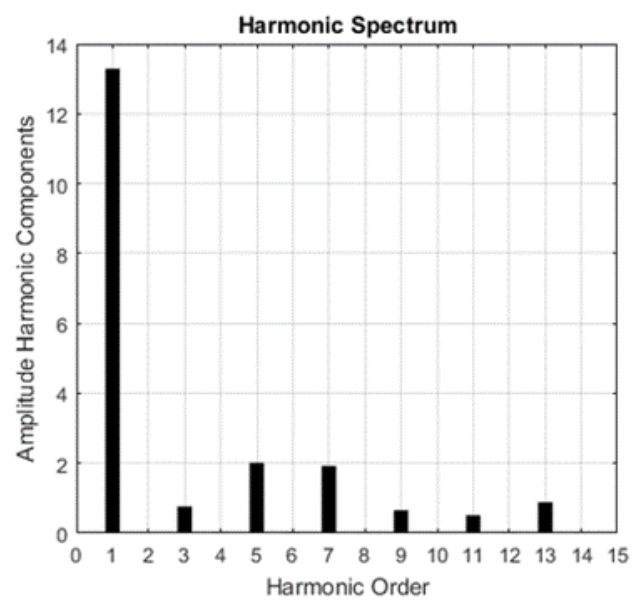

(a)

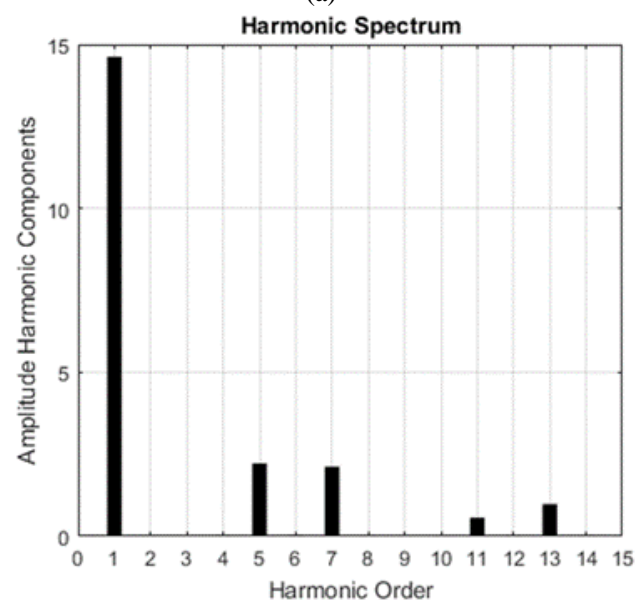

(b)

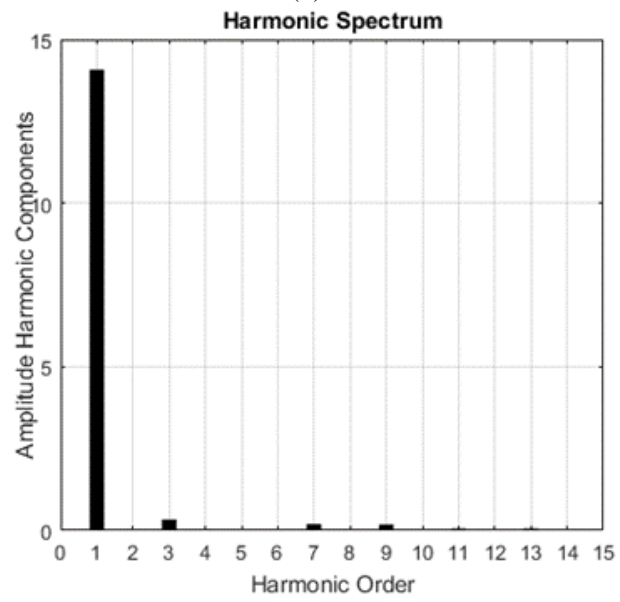

(c)

Fig. 4. Harmonics spectrum of motors in phase voltage a) 4pole/6slot, b) 4pole/12slot, c) 4pole/15slot

\section{Acknowledgment}

This paper is an extended version of work published in $8^{\text {th }}$ International Conference on Advanced Technologies (ICAT2019). 


\section{References}

[1] D. Hanselman, Brushless Permanent Magnet Motor Design 2nd Ed., Magna Physics Publishing, Ohio, pp.1-51, 2006.

[2] A. Saygın, C. Ocak, A. Dalcalı and E, Çelik, "Optimum Rotor Design of Small PM BLDC Motor Based on High Efficiency Criteria," ARPN Journal of Engineering and Applied Sciences, Vol. 10 (19), pp. 9127-9132, 2015.

[3] A. Dalcal1, "Design and optimization of brushless direct current motor for rotary cryogenic coolers," M. Sc. Thesis, Gazi University, Ankara, Turkey, 2013.

[4] A. M. Ajamloo, A. Ghaheri, E. Afjei, "Multiobjective Optimization of an Outer Rotor BLDC Motor Based on Taguchi Method for Propulsion Applications," 10th International Power Electronics, Drive Systems and Technologies Conference, pp. 34-39, 2019.

[5] Y. B. Adyapaka Apatya, A. Subiantoro and F. Yusivar, "Design and Prototyping of 3-Phase BLDC Motor," 15th Intl. Conf. QiR: Intl. Symp. Elec. and Com. Eng, pp. 209-214, 2017.

[6] S. Sakunthala, R. Kiranmayi and P. N. Mandadi, “A Study on Industrial Motor Drives Comparison and Applications of PMSM and BLDC Motor Drives," International Conference on Energy, Communication, Data Analytics and Soft Computing, pp. 537-540, 2017.

[7] M. N. Gujjar and P. Kumar, "Comparative analysis of Field oriented control of BLDC motor using SPWM and SVPWM techniques," 2nd IEEE International Conference on Recent Trends in Electronics Information \& Communication Technology, pp. 924-929, 2017.

[8] J. S. Park, K. D. Lee, S. G. Lee and W. H. Kim, "Unbalanced ZCP Compensation Method for Position Sensorless BLDC Motor," IEEE Transactions on Power Electronics, Vol. 34(4), pp. 3020-3024, 2019.

[9] W. Han, Y. Y. Ko, M. K. Seo, Y. J. Kim, S. Y. Jung, "Structural Design Methodology of BLDC Motor Considering Response Time of Phase Current," 21st International Conference on Electrical Machines and Systems, pp. 248-251, 2018.

[10] Y. U. Park, D. K. Kim, “Analytical prediction of the cogging torque in external-rotor single-phase BLDC motors with tapered air-gap," International Journal of Applied Electromagnetics and Mechanics, Vol. 1, pp. 1-8, 2018.
[11]H. Y. Lee, B. C. Jeon, W. K. Park and S. C. Lee, "Design and Verification of Sensorless BLDC Motor Start-up Logic with FPGA," International SoC Design Conference, pp. 341-342, South Korea, 2016.

[12] B. V. R. Kumar and K. S. Kumar, "Design of A New Dual Rotor Radial Flux BLDC Motor with Halbach Array Magnets for an Electric Vehicle," IEEE International Conference on Power Electronics, Drives and Energy Systems, India, 2016.

[13]E. Carraro, S. Zhang and Koch, "Design and performance comparison of fractional slot concentrated winding spoke type synchronous motors with different slot-pole combinations," IEEE Transactions on Industry Applications, Vol. 54(3), 2276-2284, 2018.

[14] H.W. Jun, H. S. Seol and J. Lee, "Effect of poleslot combination on eddy-current formation in PMSM rotor assembly including retaining plate structure,". IEEE Transactions on Magnetics, Vol. 53(11), 2017.

[15] S. Jafarishiadeh, M. Ardebili and A. N. Marashi, "Investigation of pole and slot numbers in axial-flux pm BLDC motors with single-layer windings for electric vehicles," 24th Iranian Conference on Electrical Engineering, Iranian, 2016.

[16] A. A. Rajan, S. Vasantharathna, "Harmonics and Torque Ripple Minimization using L-C Filter for Brushless DC Motors," International Journal of Recent Trends in Engineering, Vol 2(5), 239-243, 2009.

[17] M. A. Doss, E. Premkumar, G. R. Kumar, J. Hussain, "Harmonics and Torque Ripple Reduction of Brushless DC Motor (BLDCM) using Cascaded H-Bridge Multilevel Inverter," International Conference on Power, Energy and Control, 296299, 2013.

[18]H. S. Kim, Y. M. You, B. I. Kwon, "Rotor Shape Optimization of Interior Permanent Magnet BLDC Motor According to Magnetization Direction," IEEE Transactions on Magnetics, Vol. 49(5), 2013.

[19]B. I. Kwon, "Investigation of slot-pole combinations on IPM BLDC motor considering magnetization direction," International Journal of Applied Electromagnetics and Mechanics, Vol. 1, 1-8, 2018.

[20] P. Upadhayay, K. R. Rajagopal, "Torque ripple reduction using magnet pole shaping in a surface mounted Permanent Magnet BLDC motor," International Conference on Renewable Energy Research and Applications, pp. 516-521, 2013. 
[21]C. Ocak, "Design and Performance Comparison of Four-Pole Brushless DC Motors with Different Pole/Slot Combinations," The International Journal of Energy \& Engineering Sciences, Vol. 3(3), pp. 69-78, 2018.

[22] A. Dalcalı and M Akbaba, "Optimum pole arc offset in permanent magnet synchronous generators for obtaining lowest voltage harmonics," Scientia Iranica D, Vol. 24(6), pp.3223-3230, 2017.

[23]R. Ingale, "Harmonic Analysis Using FFT and STFT," International Journal of Signal Processing, Image Processing and Pattern Recognition, Vol. 7(4), pp. 345-362, 2014.

[24] W. C. Lo, C. C. Chan, Z. Q. Zhu, L. Xu, D. Howe and K. T. Chau, "Acoustic noise radiated by PWMcontrolled induction machine drives," IEEE Transactions on Industrial Electronics, Vol. 47 (4), pp. 880-889, 2000.

[25] A. Mollaeian, S. M. Sangdehi, A. Balamurali, G. Feng, J. Tjong and N. C. Kar, "Reduction of space harmonics in induction machines incorporating rotor bar optimization through a coupled IPSO and 3-D FEA algorithm," XXII International Conference On Electrical Machines, pp. 557-563, Lausanne, 2016.

[26] V. Kindl, K. Hruska, J. Sobra and M. Byrtus, "Effect of induction machine's load and rotor eccentricity on space harmonics in the air gap magnetic flux density," 16th International Conference on Mechatronics-Mechatronika, pp. 463-468, Brno, 2014.

[27] V. I. Patel, J. Wang, W. Wang and X. Chen, "Analysis and design of 6-phase fractional slot per pole per phase permanent magnet machines with low space harmonics," IEEE International Electric Machines \& Drives Conference, pp. 6-13, Chicago, 2013.

[28]Ö. Şenyurt, " Harmonic analysis determined with fast fourier transform on electric networks," M. Sc. Thesis, Gazi University, Ankara, Turkey, 2006.

[29] C. Kocatepe, M. Uzunoğlu, R. Yumurtacı, A. Karakas, and O. Arıkan, Harmonics in Electrical Installations, Birsen Publication, ISBN: 975-511354-1, 2003.

[30] A. A. Pop, H. Balan and M. Radulescu, "Fluxdensity space-harmonics minimization for an axialflux permanent-magnet machine," 4th International Symposium on Electrical and Electronics Engineering, Romania, 2013. 